\title{
The Tulving-Wiseman law and the recognition of recallable music
}

\author{
JOHN M. GARDINER, ZOFIA KAMINSKA, ROSALIND I. JAVA, \\ ERIC F. CLARKE, and PETER MAYER \\ City University, London, England
}

\begin{abstract}
Memory for well-known musical phrases was tested first for recognition in the absence of any specific musical context and then for recall given the preceding musical phrase as a contextual cue. Recognition and recall were found to be largely, but not completely, independent. Moreover, there was no evidence of any greater dependency between recognition and recall than that previously observed in the relation between word recognition and recall, as summarized by the Tulving-Wiseman law. These findings significantly extend the range of applicability of this law.
\end{abstract}

It has been claimed that there is an empirical law in the relation between recognition and recall. This law has come to be known as the Tulving-Wiseman law, after those who discovered the regularity that it embodies (Tulving \& Wiseman, 1975). Tulving and Wiseman proposed that this regularity could be summarized mathematically by the following equation:

$$
p(R n / R c)=p(R n)+c\left[p(R n)-p(R n)^{2}\right],
$$

where the constant $c=.5$. In this equation, the relation between recognition and recall is assessed by the conditional probability of recognition $(R n)$ given recall $(R c)$, and the relation is one in which recognition and recall are largely, but not completely, independent.

The claim that this relation between recognition and recall is lawful has been recently discussed by Gardiner (1988, 1989), Jones and Gardiner (1990), Nilsson, Dinniwell, and Tulving (1987), and Nilsson, Law, and Tulving (1988). But the fullest review has been provided by Gardiner and Nilsson (1990), who state the law as follows:

Recognition of a set of to-be-remembered items in the absence of any item-specific context is largely independent of their subsequent recall given item-specific contextual cues-provided these cues are functionally related to, but not equivalent to, the target items themselves.

Gardiner and Nilsson reviewed results from 78 relevant experiments from 42 published articles. These experiments yielded a total of 272 different observations of the probability of recognition given recall, and-with few exceptions-these observations all corresponded approximately with the probability of recognition given recall that would be expected, on the basis of Equation 1, from the probability of recognition. The experiments naturally

We thank Ian Cross for help in computer programming and James Hampton and Paul Williams for help in recording the music. Requests for reprints should be addressed to John Gardiner, Memory \& Cognition Research Group, City University, Northampton Square, London EC1V OHB, England. differed with respect to a great many variables that separately influenced recognition and recall performance. The lawfulness arises from the fact that the relation between recognition and recall remains relatively intact, despite this variability.

All those experiments, however, conform to a particular experimental situation that was worked out by Tulving and Thomson (1973) and Watkins and Tulving (1975). Typically, subjects study a list of target words, each of which is accompanied by a contextual word that they are told will be presented as a recall cue in a later test. Subjects are then given successive tests for the recognition of target words in the absence of the contextual cues and for the recall of target words given those cues. As is well known, the finding that subjects often fail to recognize words that they can recall was used initially to argue against generate-recognize theories of recall, which predict a relation of dependency between recognition and recall. According to these theories, any item in a recallable state is also in a recognizable state, because recall entails an implicit recognize stage, as well as a generate stage (for reviews, see Tulving, 1983; Watkins \& Gardiner, 1979). Thus, according to generate-recognize theories, the probability of recognition given recall should always approximate 1.00 .

Although the Tulving-Wiseman law holds generally in this experimental situation, a few exceptions have been observed. These exceptions are cases in which the observed probability of recognition given recall is appreciably greater than expected.

There are two kinds of exception. One occurs when the contextual cues are not encoded in relation to their targets. In this case, the cues provide no additional contextual information and so they do not function as effective cues. In these circumstances, a nominally cued-recall test is functionally like free recall. Exceptions of this kind have been reported by Begg (1979) and by Gardiner and Tulving (1980), among others.

The second kind of exception occurs when the contextual cues are functionally equivalent to the targets in the 
sense that the contextual information provided by the cue is largely inherent in the target. In these circumstances, a nominally uncued-recognition test is functionally like a cued-recognition test, because the contextual information in the cue can be retrieved from the target. Contextual cues will therefore again be ineffective, but now in comparison with recognition rather than with free recall. Exceptions of this kind have been reported by Jones and Gardiner (1990), Muter (1984), and Nilsson and Shaps (1980).

Gardiner and Nilsson (1990) argue that these exceptions constitute the only known, principled, systematic deviations from Equation 1. These exceptions therefore define the specific boundary conditions of the Tulving-Wiseman law, and it was for this reason that Gardiner and Nilsson referred to these exceptions in their statement of the law.

An empirical law of this kind formulates what will happen in a particular situation under given conditions. Any such law therefore has a set of boundary conditions that restrict its range. The most important theoretical issue concerning this kind of empirical law is its range of applicability. This is the issue addressed in the present article. The research we describe was motivated by the fact that the Tulving-Wiseman law is based entirely on the results of word-list experiments. Our purpose was to determine whether the law is necessarily restricted to verbal materials or whether it extends to some nonverbal domain. Therefore, we decided to investigate the relation between the recognition and recall of music.

\section{EXPERIMENT 1}

We report two experiments, each of which was modeled on Muter's (1984) study. Muter's study was a semantic memory version of the basic procedure. There was no study list. Subjects were given a recognition test for names of famous people, some of whom had unique names (e.g., Ataturk) and some of whom had common names (e.g., Cooper). Subjects had to indicate which names they recognized were names of famous people. There was then a cued-recall test in which the cues were descriptive phrases embodying the main reason for each person's fame (e.g., "First president of the republic of Turkey, Kemal: "; "Author of The Last of the Mohicans, James Fennimore: "). Muter found that for a common name such as Cooper, the probability of recognition given recall was much as expected from Equation 1 , but that for a unique name the probability of recognition given recall was virtually 1.00 . He interpreted this result as supporting a version of generate-recognize theory according to which recognition is dependent on recall only for words of single meaning (see, e.g., Reder, Anderson, \& Bjork, 1974). In this version of the theory, words of single meaning are assumed to have only one representation in semantic memory, and access to that one representation is assumed not to be influenced by contextual differences between recognition and recall.
However, in recognizing Ataturk as the name of a famous person, subjects presumably retrieved information about the reasons for his fame, and so retrieved much of the information subsequently provided by the cue. Evidence suggesting that Muter's (1984) results were due not to any representational properties of the names as assumed by generate-recognize theory but to overlap in the contextual information provided by the target and the cue was reported by Nilsson et al. (1988), who showed that, when the contextual cues were less predictable from the targets, the relation between the recognition and recall of unique famous names was much as expected from Equation 1.

In our experiments, the subjects were first given a recognition test for musical phrases taken from wellknown tunes or themes, and they had to indicate which phrases they recognized. They were then given a recall test in which each contextual cue was the immediately preceding musical phrase from the particular tune or theme. Target phrases for recognition and recall were selected so as to avoid using phrases that were repetitious or otherwise directly predictable from the preceding contextual phrase. These phrases were also selected so as to be not only recognizable, but recognizably unique in the sense that each one appears in only one well-known tune or theme. For example, phrases taken from "Rule Brittannia" or from the first movement of Mozart's Symphony No. 40 in G Minor do not figure in any other wellknown piece of music

What little is known about memory for music, in particular memory for melodies, largely involves short-term memory for novel or unfamiliar melodies (e.g., Balch, 1984; Dewitt \& Crowder, 1986; Dowling, 1986; Jones, Sumereall, \& Marshburn, 1987; Roberts, 1986; Serafine, Davidson, Crowder, \& Repp, 1986). How does one gain access to phrases from well-known tunes or themes represented in semantic memory? One possibility, suggested by generate-recognize theory, is that such musical phrases are represented in such a way that one gains direct access to each phrase on hearing it. If this is so, recognition should be highly dependent on recall, and the recognition of recallable music should be essentially perfect. This outcome would provide good support for a generate-recognize theory account of the relation between the recognition and recall of music, and it would indicate that the Tulving-Wiseman law may be restricted to the verbal domain. Alternatively, of course, the relation between the recognition and recall of musical phrases may be much the same as that between the recognition and recall of words. If this is so, the probability of recognition given recall should be much as expected from Equation 1.

\section{Method}

Subjects. The subjects were 18 undergraduate students at City University, London. They were paid for their help and were tested individually.

Design and Materials. A set of 18 melodies was selected on the basis of pilot work indicating that these melodies were highly 
familiar to the population of subjects tested. These melodies were from well-known folk songs, carols, hymns, and nursery rhymes. Their titles are listed in full in the Appendix. The first major section of each melody was divided into " $A$ " and " $B$ " phrases, not arbitrarily, but according to music criteria, that is, between rather than within larger phrase boundaries. The B phrases served as target phrases for recognition and recall; the A phrases served as recall cues. The recognizability of each target phrase and its recallability given the cue were also independently confirmed in pilot work. The target phrases were on average 6.8 notes in length (range $=5-12$ notes). In the recognition test, these phrases were randomly mixed together with 18 comparable phrases taken from Polish folk songs and carols that, though well known in Poland, are not well known in England. These lure phrases were on average 7.2 notes in length (range $=4-10$ notes). Target and lure phrases were recorded in two unique random orders; half of the subjects received one presentation order and half received the other. The subjects were told to listen to each phrase and judge whether they recognized it as a phrase from a well-known tune. For the recall test, the $18 \mathrm{~A}$ phrases were recorded in two unique random orders; half of the subjects received one presentation order and half received the other. The cue phrases were on average 8.3 notes in length (range $=6-16$ notes). The subjects were told to use each phrase as a cue to recalling the next phrase from the tune.

Procedure. All musical phrases were single-line melodies played on a Casio synthesizer and recorded on a Sony cassette, from which they were played back to the subject through a set of headphones. The subjects' responses in the recall test were recorded on another Sony cassette.

In the recognition test, the subjects were told that they were going to hear a series of excerpts from tunes that either were fairly well known and familiar or were unfamiliar. Immediately after hearing each phrase, the subjects indicated whether they recognized the phrase using a 6-point rating scale ranging from +3 (highly familiar) to -3 (very unfamiliar). Familiar phrases (rated $+1,+2$, or +3 ) were defined as those which the subjects recognized, in the sense that they knew the piece of music in which the phrase appears; for unfamiliar phrases (rated $-1,-2$, or -3 ), the converse definition applied. In the recall test, which followed directly, the subjects were told that each phrase was taken from the beginning of a well-known tune featured in the earlier part of the experiment and that, after listening to each phrase, they were to recall the next phrase from the tune. They were given the option of recalling the phrases by singing, humming, whistling, or "la-la"'ing. It was emphasized that the accuracy of their performance was more important than its musical qualities. The subjects sat in front of a microphone for recording their responses.

\section{Results and Discussion}

It was obvious from the subjects' recall performance whether or not they could recall the appropriate phrase, and so scoring recall presented no difficulty. The subjects were not penalized for minor errors, such as omitting one particular note or drifting somewhat off key. The principal results, collapsed over the midpoint of the rating scale, are summarized in Table 1 (upper half) and Table 2 (left-hand columns). Table 1 shows the overall response frequencies; Table 2 shows the probabilities of recognition, of recall, and of recognition given recall-the observed value and the value expected from Equation 1. All entries in Tables 1 and 2 reflect the fates of individual items. The mean values in Table 2 are based on values calculated separately for each individual subject, not on the aggregate data summarized in Table 1 . The average false-positive rate in the recognition test, which is not
Table 1

Overall Response Frequency

\begin{tabular}{lccr}
\hline & Recalled & Not Recalled & Total \\
\hline & Experiment 1 & & \\
Recognized & 199 & 51 & 250 \\
Not Recognized & 45 & 29 & 74 \\
Total & 244 & 80 & 324 \\
& Experiment 2 & & \\
Recognized & 120 & 21 & 141 \\
Not Recognized & 82 & 47 & 129 \\
Total & 202 & 68 & 270 \\
\hline
\end{tabular}

Table 2

Probability of Recognition, Recall, and Recognition Given Recall

\begin{tabular}{lccccc}
\hline & \multicolumn{2}{c}{ Experiment 1} & & \multicolumn{2}{c}{ Experiment 2 } \\
\cline { 2 - 3 } \cline { 5 - 6 } & $M$ & SEM & & $M$ & SEM \\
\hline Recognition (Rn) & .76 & .03 & & .52 & .05 \\
Recall (Rc) & .75 & .03 & .74 & .03 \\
Expected Rn/Rc & .85 & .02 & .64 & .05 \\
Observed Rn/Rc & .81 & .02 & .59 & .05 \\
\hline
\end{tabular}

shown in these tables, was .35; all subjects scored considerably more hits than false positives.

The results summarized in Tables 1 and 2 show that the subjects were able to recall much the same proportion of phrases that they were able to recognize, but that these were not all the same actual phrases. That is, the subjects successfully recalled quite a few phrases that they failed to recognize. Moreover, the observed probability of recognition given recall corresponds fairly closely with the expected value. Importantly, these measures of recognition given recall provide no evidence of any greater dependency between recognition and recall than that which has previously been found in the relation between word recognition and recall. This outcome provides no support for the possibility that generate-recognize theory might be able to account for the recognition and recall of music. Instead, it extends the range of applicability of the Tulving-Wiseman law from verbal to musical items.

\section{EXPERIMENT 2}

Although presented in purely musical form, the melodies used in Experiment 1 have associated texts or lyrics. In recognizing phrases from these melodies, the subjects may well have implicitly retrieved some of this verbal information. It is known that memory for melody and text is integrated, at least in recognizing unfamiliar folk songs (see, e.g., Serafine et al., 1986). So it seems possible that, to some extent, the relation between the recognition and recall of the music may have been mediated by knowledge of the associated text or lyrics. Accordingly, Experiment 2 was designed to test the replicability of Experiment 1 when the melodies used had no text or lyrics. These melodies all consisted of well-known themes from classical music. 


\section{Method}

Subjects. The subjects were 18 undergraduate students at City University, London. They were paid for their help and were tested individually. None of the subjects in Experiment 2 had participated in Experiment 1.

Design and Materials. The design was essentially the same as that in Experiment 1, but the materials were different. A set of 15 melodies was selected on the basis of pilot work indicating that these melodies were quite familiar to the population of students tested. This was a set of slightly fewer melodies than that used in Experiment 1 , because it proved to be more difficult here to find melodies that were sufficiently well known to be used. These melodies were all themes from pieces of classical music, as cited by Barlow and Morgenstern (1983). They are listed in full in the Appendix. Each of these themes was divided into A and B phrases, as in Experiment 1 , for use as recall cues and recognition and recall targets. As in Experiment 1, the recognizability of each target phrase and its recallability given the cue were confirmed in pilot work. The target phrases were on average 12.1 notes in length (range = 8-24 notes). In the recognition test, these target phrases were randomly mixed together with 15 comparable lures. The lure phrases were other themes cited by Barlow and Morgenstern from relatively unknown pieces of music by the same composers whose music provided the target phrases. The lure phrases were on average 12.7 notes in length (range $=9-28$ notes). The cue phrases in the recall test were on average 11.5 notes in length (range $=7-20$ notes).

Procedure. The procedure was also essentially the same as in Experiment 1, except for the instructions in the recognition test. A preliminary version of the experiment revealed that subjects were occasionally prone to say that they "recognized" a phrase when they meant only that they recognized the musical style or period rather than the specific phrase and the theme in which it occurs. So the subjects were instructed that it was not sufficient just to recognize the composer's style or the period in which the music was probably composed. They were told: "You must recognize the specific theme from which the excerpt is taken. This does not mean knowing the number of the opus or symphony or its name. You may, for example, recognize that the excerpt is from one of Elgar's bestknown orchestral works, but not remember which one it is. The important thing is to be sure you do recognize the particular excerpt from a familiar piece of music." The subjects were also told that all the excerpts they were to hear in this test were from pieces by well-known composers, some of which were their best-known compositions and some of which were their least known compositions.

The recall test was conducted in the same manner as before. One subject turned out to be incapable of rendering any kind of musically intelligible performance. This subject quit and was replaced There were also a few occasions on which the subjects did not produce the complete phrase as designated and stopped after producing only part of it or merely repeated the cue. On these occasions, the subjects were required to continue until they had produced the complete target phrase.

\section{Results and Discussion}

Scoring recall performance presented no difficulty in deciding whether the subjects had recalled the appropriate phrase and, as in Experiment 1, the subjects were not penalized for slight errors, such as omitting an occasional note or deviating somewhat from the correct rhythm. The principal results are summarized in Table 1 (lower half) and Table 2 (right-hand columns). The average falsepositive rate in the recognition test was .17, appreciably less than that in Experiment 1. All but 1 subject scored more hits than false positives; this subject scored an equal number of each.

The results show that recognition, but not recall, was lower in Experiment 2 than in Experiment 1; however, in other respects, the findings are similar. The subjects again successfully recalled quite a few phrases that they had failed to recognize. The observed probability of recognition given recall again corresponds fairly closely with the expected value. There is again no evidence of any greater dependency between recognition and recall than that predicted by the Tulving-Wiseman law. The relation between the recognition and recall of these musical phrases was essentially the same as that in Experiment 1. It may be concluded that this relation also obtains when the music has no associated text or lyrics.

\section{GENERAL DISCUSSION}

The purpose of the experiments described in this article was to test the generality of the Tulving-Wiseman law. Hitherto, this law has been observed only in experiments using word lists. This fact raises the question of whether the law is necessarily restricted to the verbal domain or whether it applies to other domains. The results of the experiments demonstrate that the law extends to the recognition and recall of musical phrases. This extension of the generality of the Tulving-Wiseman law significantly increases its theoretical importance.

It is of interest to compare our results more directly with results from some of the experiments that have used verbal materials. ${ }^{1}$ Figure 1 reproduces results from 40 different conditions in the first 12 such experiments, as

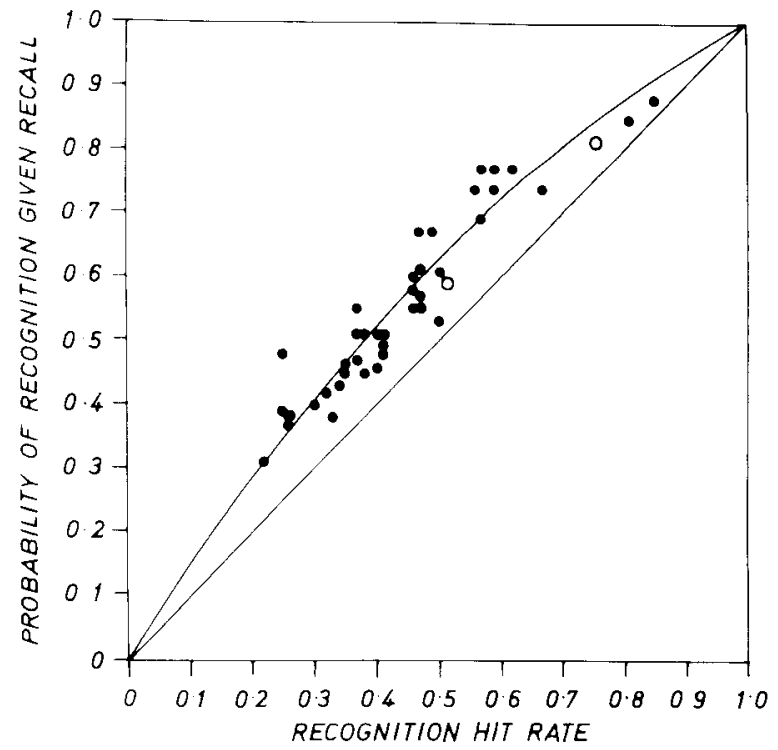

Figure 1. Probability of recognition given recall as a function of recognition hit rate. Based on Tulving and Wiseman's (1975) Figure 1. 
summarized by Tulving and Wiseman (1975). To this, we have added our results, which are shown by the open, unfilled data points.

An empirical law summarizes a considerable, coherent set of observations. But, insofar as it is predictive and it gives understanding, it also has explanatory value. The explanation lies simply in the statement or description of the law. In this case, one can say that successive recognition and recall of the same set of items will always be largely independent-approximately to the extent predicted by Equation 1-whenever the recall environment includes effective contextual cues that were not present in the recognition environment.

Although empirical laws may be regarded as an alternative form of explanation (see Watkins, 1990), they are, of course, also open to explanations of a more familiar and conventional sort. For example, Flexser and Tulving (1978) proposed a computer simulation model of the function that is embodied in the Tulving-Wiseman law. In this model, one assumption is that of retrieval independence in recognition and recall. That is, knowing what critical features are encoded from the target in the recognition test does not predict what critical features will be encoded from the cue in the recall test. On its own, this assumption produces complete independence between the tests. But the relation observed is one of slight or moderate dependency. Another assumption accounts for this degree of dependency, which is the assumption that retrieval in each test is directed at the same memory trace. Also, success at retrieval in each test is assumed to depend on the encoding specificity principle. This model proved remarkably successful in mimicking the observed relation between recognition and recall. Furthermore, in other tests of their model, Flexser and Tulving showed that when the assumption of retrieval independence is relaxed, so that features encoded from the recall cue become predictable from features encoded from the recognition target, then the relation between recognition and recall becomes much more dependent. This corresponds with the situation in which the recall cue is functionally equivalent to the recognition target. Interestingly, the Flexser-Tulving model may also be used as a more general theoretical framework for understanding the relation between performance in any two successive tests. For example, the model can be used to interpret observations of complete independence between successive tests as evidence for a "traceless" memory system (see Hayman \& Tulving, 1989).

Despite the achievement of the Flexser-Tulving model, other models can also account for the Tulving-Wiseman law. Jones $(1978,1983)$, for example, has developed a dual-mechanism model of recall that provides an alternative account (see also Jones \& Gardiner, 1990). And the law can be readily accommodated by quite a few other, general models of memory-albeit with somewhat varying degrees of success-as Ratcliff and McKoon (1989) have recently shown. So the existence of this empirical law is consistent with many current theoretical ideas about memory function.

The theoretical rationale for the experiments described in this article, however, did not stem from theorizing of this sort. These experiments were motivated by the importance of determining the range of applicability of the Tulving-Wiseman law. And, in demonstrating that the law holds not just for the recognition and recall of words but also for the recognition and recall of music, our findings suggest that, provided the specific conditions of the law are met, it may hold true for any kind of to-be-remembered item whatsoever.

\section{REFERENCES}

BALCH, W. R. (1984). The effects of auditory and visual interference on the immediate recall of melody. Memory \& Cognition, 12, 581-589.

BARLOW, H., MoRgenSTERN, R. (1983). A dictionary of musical themes. London: Faber \& Faber.

BEGG, I. (1979). Trace loss and the recognition failure of unrecalled words. Memory \& Cognition, 7, 113-123.

DEWITT, L. A., \& CrowDER, R. G. (1986). Recognition of novel melodies after brief delays. Music Perception, 3, 259-274.

Dowung, W. J. (1986). Context effects on melody representation: Scalestep versus interval representations. Music Perception, 3, 281-296.

FleXSER, A. J., \& TulviNG, E. (1978). Retrieval independence in recognition and recall. Psychological Review, 85, 153-171.

GARDINER, J. M. (1988). Recognition failures and free-recall failures: Implications for the relation between recall and recognition. Memory \& Cognition, 16, 446-451.

Gardiner, J. M. (1989). The Tulving-Wiseman law and exceptions to it. In A. F. Bennett \& K. M. McConkey (Eds.), Cognition in individual and social contexts (pp. 253-260). Amsterdam: NorthHolland

Gardiner, J. M., \& NiLsson, L. G. (1990). Relation between recognition and recall: The Tulving-Wiseman law. Manuscript submitted for publication.

Gardiner, J. M., \& Tulving, E. (1980). Exceptions to recognition failure of recallable words. Journal of Verbal Learning \& Verbal Behavior, 19, 194-209.

Hayman, C. A. G., Tulving, E. (1989). Is priming in fragment completion based on a "traceless" memory system? Journal of $E x$ perimental Psychology: Learning, Memory, \& Cognition, 15, 941-956.

JoNEs, G. V. (1978). Recognition failure and dual mechanisms in recall. Psychological Review, 85, 464-469.

JONES, G. V. (1983). Structure of the recall process. Philosophical Transactions of the Royal Society, London B, 302, 373-385.

Jones, G. V., \& GARdiner, J. M. (1990). Recognition failure when recognition targets and recall cues are identical. Bulletin of the Psychonomic Society, 28, 105-108.

Jones, M. R., Sumereall, L., \& Marshburn, E. (1987). Recognizing melodies: A dynamic interpretation. Quarterly Journal of Experimental Psychology: Human Experimental Psychology, 39, 89-121.

MUTER, P. (1984). Recognition and recall of words with a single meaning. Joumal of Experimental Psychology: Learning, Memory, \& Cognition, 10, 198-202.

Nilsson, L.-G., Dinniwell, M., \& Tulving, E. (1987). Recognition failure of categorized words. Memory \& Cognition, 15, 389-396.

Nilsson, L.-G., LAw, J., \& Tulving, E. (1988). Recognition failure of recallable unique names: Evidence for an empirical law of memory and learning. Joumal of Experimental Psychology: Learning, Memory, \& Cognition, 14, 266-277.

Nilsson, L.-G., \& Shaps, L. (1980). A functional view of memory. In F. Klix \& J. Hoffman (Eds.), Interdisciplinary research of human memory. Berlin: DVW. 
RATCLFF, R., \& MCKoon, G. (1989). Memory models, text processing, and cue-dependent retrieval. In H. L. Roediger, III, \& F. I. M. Craik (Eds.), Varieties of memory and consciousness: Essays in honour of Endel Tulving. Hillsdale, NJ: Erlbaum.

Reder, L. M., Anderson, J. R., \& Bjork, R. A. (1974). A semantic interpretation of encoding specificity. Joumal of Experimental Psychology, 102, 648-656.

RoBerTs, L. A. (1986). Modality and suffix effects in memory for melodic and harmonic musical materials. Cognitive Psychology, 18 , 123-157.

Serafine, M. L., Davidson, J., Crowder, R. G., \& Repp, B. H. (1986). On the nature of melody-text integration in memory for songs. Journal of Memory \& Language, 25, 123-135.

Tulving, E. (1983). Elements of episodic memory. Oxford: Clarendon.

Tulving, E., \& Thomson, D. M. (1973). Encoding specificity and retrieval processes in episodic memory. Psychological Review, 80 , 352-373.

TUlviNG, E., \& WISEMAN, S. (1975). Relation between recognition and recognition failure of recallable words. Bulletin of the Psychonomic Society, 6, 79-82.

Watkins, M. J. (1990). Mediationism and the obfuscation of memory. American Psychologist, 45, 328-335.

WatKINS, M. J., \& Gardiner, J. M. (1979). An appreciation of generate-recognize theory of recall. Journal of Verbal Learning \& Verbal Behavior, 17, 621-633.

WatKINS, M. J., TULVING, E. (1975). Episodic memory: When recognition fails. Journal of Experimental Psychology: General, 1, 5-29.

\section{NOTE}

1. We are indebted to Endel Tulving for this suggestion.

\section{APPENDIX}

\section{Experiment 1: Materials}

"All Things Bright and Beautiful"

"Au Clair de la Lune"

"Clementine",

"Ding Dong Merrily on High"

"Frère Jacques"

"Good King Wenceslas"

"Green Grow the Rushes-O"
"Greensleeves"

"In the Bleak Midwinter"

"London's Burning"

"My Bonnie Lies over the Ocean"

"O Little Town of Bethlehem"

"Onward Christian Soldiers"

"Pop Goes the Weasel"

"Rule Britannia"

"Sing a Song of Sixpence",

"The Happy Wanderer"

"While Shepherds Watched"

\section{Experiment 2: Materials}

Bach: Jesu Joy of Man's Desiring; 1st Movement, 1st Theme.

Beethoven: Für Elise; Opening Theme.

Bizet: L'Arlesienne, Suite No. 1; Overture, 1st Theme.

Bizet: $\quad$ Carmen; Prelude to Act 1, Ist Theme.

Grieg: Peer Gynt, Suite No. 1; 1st Movement, Morning Mood.

Grieg: Peer Gynt, Suite No. 1; 4th Movement, In the Hall of the Mountain King.

Mozart: $\quad$ Symphony No. 40; 1st Movement, lst Theme.

Offenbach: Orpheus in Hades; Galop, 2nd theme.

Prokofiev: Lieutenant Kije; 4th Movement, Troika

Prokofiev: Peter and the Wolf; 1 st Theme, Peter.

Ravel: $\quad$ Bolero; Theme A.

Strauss: Waltzes from Die Fledermaus; No. 1, 1 st Theme.

Suppe: $\quad$ Light Cavalry Overture; 3rd Theme.

Tschaikovsky: 1812 Festival Overture; 2nd Theme.

Tschaikovsky: Swan Lake, Suite from the Ballet; 3rd Movement, Dance of the Swans.

(Manuscript received September 11, 1989; revision accepted for publication May 9, 1990.) 